\title{
A CASE OF LARGE TUMOUR OF THE LEFT CEREBRAI HEMISPHERE, WITH REMARKABLE REMISSIONS IN THE SYMPTOMS.
}

\author{
BY J. BURNEY YEO, M.D., F.R.C.P., \\ Phyrician to King's Collego Hospital.
}

IN the middle of June 1877, a lady, fifty-nine years of age, came under my care, complaining of the following symptoms: general loss of power, especially of the lower half of the body, her right lower limb being chiefly affected; the right foot was lifted from the ground slowly and with difficulty, and the toe dragged in walking. The upper part of the body showed no very appreciable muscular paralysis, although the grasp of the right hand was a little weaker than that of the left, and sensibility all over the right side was undoubtedly diminished.

The patient's mental faculties, which were usually bright and active, and accompanied with much facility in expressing her ideas, were decidedly obscured, and she had great difficulty in finding words to express the simplest idess. She was much distressed by this difficulty in finding words. She could not write a letter; not only had she difficulty in managing her pen from loss of sensibility in the hand, but she obviously could not command words, and her attempts resulted in an incoherent scrawl, in which a few words only could be recognised.

Her memory was greatly impaired, and although she would attend to and take an interest in what was read to her, she would almost immediately forget it, and take the same interest in its repetition. She appeared capable of recognising external objects, but failed in any close attention to them : e.g., when asked if she could tell the time by a watch, she would say, "Oh yes, very well;" and then when a large watch was presented to her, after looking at it for a moment or two, she would put her hand to her head, and simply look distressed. At this period there was very little complaint of headache or of sickness. 
I obtained the following history of her illness from her friends :- She had left England about three months before in fair health, to visit some relatives in the east of Europe; and it was during the homeward journey, after a successful tour, that the first symptoms of her illness appeared. The earliest sign noticed was in a letter received by one of her relatives, written at Malta, which was a little incoherent and badly expressed, and contrasted strongly with her usually carefully written and well-expressed letters. At Gibraltar, after a long walk, she appears to have been attacked with partial hemiplegia, for she was found sitting on the floor in her dressingroom, and it was then particularly noticed that she found much difficulty in finding words, and that her memory had become very defective.

She appears to have recovered partially from this incomplete hemiplegia, but there continued to be much loss. of power about the lower part of the trunk, and she remained during the rest of the homeward journey much in the seme condition as when I saw her in June, immodiately after her arrival.

For a few days after my first visit she continued to be tolerably cheerful, and appeared to take an interest in things around her, and conversed with her relatives and friends; but an attempt to drive in the open air was followed by complaint of severe pain in the head, and the next day a state of complete mental apathy came on, from which it wes impossible to rouse her to take an interest in anything. She lay with her eyes closed, pupils equal and sensitive, breathing slowly but regularly, with a good, steady pulse, and taking small quantities of food mechanically. She remained in this low and apathetic state for about a fortnight, giving rise to much anxiety whether she would ever rally from it; when, on the arrival of her son from abroad, she quite suddenly recovered her mental activity and a considerable amount of muscular power. She conversed intelligently, took an interest in what was passing around her, asked questions, and appeared to recover her memory to a great extent, sat up on the sofa, and was able to use her right hand, as well as the left, to some degree. But there was not much recovery of power below the waist.

Soon after this remarkable rally some fresh symptoms made their appearance, viz. severe pains in the head, especially referred to the left side and back of the head, and troublesome vomiting.

I may mention here that croton (butyl) chloral certainly relieved the pain in the head, in from two to six grain doses. Both the romiting and the headache were greatly relieved by 
appropriate treatment, and the mental condition was remarkably influenced all through the illness by the action of the bowels. After free alvine evacuations there was always noticed a decided improvement in the mental state.

This first rally lasted between two and three weeks, when she again passed into a stato of complete mental apathy, with apparently general loss of muscular power, as on the former occasion. This lasted about ter days, when another and still more remarkable rally occurred. She sat up on the sofa, would even attempt to get off it, conversed cheerfully and collectedly, was able to take a sort of retrospect of her illness, could use both hands sufficiently well to do a little knitting, took food with relish, had no pain in the head, and no romiting. This singular improvement, which excited in her relatives and friends much hope of ultimate recovery, continued for nearly three weeks. She then again, and for the third time, somewhat suddenly passed into a state of mental obscuration, not so complete as on the former occasions; but now a curious restlessness affected the right side-the side on which the loss of power had been especially observed-the right hand and arm would be constantly making purposeless movements, and the right leg first flexed and then extended. From this recurrence of the phenomena there was never again a complete rallying as on the former occasions. There was progressive loss of muscular power, but occasional partial recovery of mental activity. About the end of September the loss of power was so general that she was obliged to keep her bed, having up to this time been dressed and moved to a couch in a sitting-room almost daily. Extensive bed-sores formed very rapidly, and were attended by a low sub-pyrexial state, from which she sank on the 14th of October, just four months after I first saw her, and about five months from the appearance of the first symptoms.

A post-mortem examination of the brain was permitted, but it had to be performed hastily, and under difficulties which precluded the possibility of a detailed examination of that organ being made.

The posterior part of the left hemisphere was greatly increased in size, and prominently bulged by the existence within its substance of a large oblong tumour (having the microscopical characters of glioma), about the size of a goose's egg, or ratber larger, and weighing nearly six ounces. It did not extend beyond the posterior half of the hemisphere; it was situated chiefly in the white substance of the posterior lobe, and quite centrally. It did not extend to the upper surface so as to reach the convolutions, nor to the inferior or inner surface, su as to interfere with any of the structures at the base of the 
brain, or in the floor of the ventricles. But owing to the greatly increased size of the left hemisphere, the structures at the bese of the brain were curiously altered in position; one half, the left, being, as it were, pushed forward, so that parts which should hare appeared horizontal (e.g. the optic commissare) had an oblique direction. I had the advantage during the course of the illness of the co-operation of Sir Wm. Gull and Dr. Hughlings-Jackson. During the early part of the illness we hesitated somewhat in expressing a positive opinion as to the precise nature of the disease; we were soon, however, convinced that we had to do with a case of cerebral tumour. The discovery on ophthalmoscopic examination of double optic neuritis confirmed our opinion. We were enabled also to trace in the family history evidence of the existence of a tendency to malignant disease.

The most remarkable feature in the course of this case was the several decided rallies to which I have called attention. The improvement was on the two first occasions so striking, and on the second occasion so long maintained, that it was with difficulty we could persuade the patient's relatives and friends that we had before us a case of inevitably fatal disease. The contral position of the morbid growth will no doubt help to account for this, as it will also account for the absence of complete hemiplegie, of any local paralysis, of convulsions, and of delirium. 